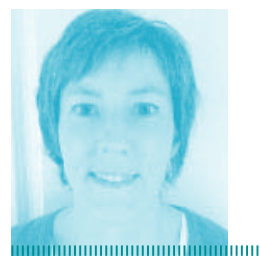

Randi Slettebø Bendiksen, klinisk spesialist i psykiatrisk sykepleie, Psykiatrisk divisjon ved Stavanger Universitetssjukehus
Svein Friis, professor i psykiatri og overlege ved Avdeling for Forskning og Utvikling, OUS
Jan Ivar Røssberg

professor i psykiatri og leder ved Regionalt Kompetansesenter for Tidlig Intervensjon ved Psykoser, OUS

\title{
Miljøtiltak ga bedre atmosfære på DPS
}

\author{
Postatmosfæren bedret seg ved målrettet arbeid med relasjonen mellom pasienter og miljøpersonalet.
}

$\mathbf{P}$ asienter med alvorlige psykiske lidelser trenger ofte en sykehusinnleggelse (1). Sykehusbehandling er dyrt og beslaglegger store deler av helsebudsjettene. Likevel vet vi lite om hva som er effektive elementer for innlagte pasienter med en psykisk lidelse og hvordan miljøet kan optimalisere behandlingen. Den viktigste enkeltfaktoren for behandlingsresultatet på sykehus er antakelig postatmosfæren (2) som miljøterapien har tatt sikte på å bedre (3). Det terapeutiske miljøet skapes gjennom relasjoner og flere undersøkelser viser at pasientene vurderer relasjonen de har til behandlingspersonalet som det viktigste i sykehusbehandlingen (4- 6). Miljøpersonalets holdninger, handlinger, ytringer, tanker og følelser slik de viser seg i samspillet med pasientene preger postatmosfæren. Undersøkelser har vist at postatmosfæren er viktig for behandlingsresultatet både på kort og lang sikt (7-11).

\section{Hovedbudskap}

Relasjonen mellom pasientene og behandlingspersonalet i psykiatriske avdelinger er viktig for behandlingsresultatet. Ved målrettet arbeid kan man forbedre behandlingsmiljøet og Ward Atmosphere Scale er et instrument som kan måle resultatene.

\section{Nøkkelord}

Les mer og finn litteraturhenvisninger på våre nettsider.

\Arbeidsmiljø \Atferd / Forebygging

> Psykisk helse

52 Sykepleien $10 \mid 2013$

\section{Måler postatmosfæren}

Ward Atmosphere Scale (WAS) er gullstandarden for å måle postatmosfæren på psykiatriske poster. WAS måler både pasientenes og personalets opplevelse av miljøet, atferd og holdninger (12). Flere studier har brukt WAS for å forbedre behandlingsklimaet i psykiatriske avdelinger. Hvis man vil oppnå store endringer i postmiljøet er det nødvendig med en mer handlingspreget tilnærming $(12,13)$. Organisatoriske endringer kan forbedre postmiljøet, men de kan også forverre det (13-16).

Hensikten med denne undersøkelsen var å finne ut om en intervensjon med sikte på å bedre pasient-miljøterapeutrelasjonen ville bedre behandlingsmiljøet på en psykiatrisk sengepost. Undersøkelsen er foretatt i en sengepost med 14 sengeplasser og tre dagplasser ved et DPS. Postmiljøet ble undersøkt ved hjelp av WAS, og det ble foretatt to målinger med ett års mellomrom.

Vi ville besvare følgende spørsmål:

1. Bedrer intervensjonen behandlingsmiljøet målt med WAS for henholdsvis pasientene og miljøterapeutene?

2. Fører intervensjonen til at pasientene blir mer fornøyde med behandlingen?

3. Fører intervensjonen til et bedre arbeidsmiljø blant miljøterapeutene?

\section{Materiale og metode}

WAS-spørreskjema ble delt ut til alle inneliggende pasienter. Pasientene var frivillig innlagt og hadde ulike psykosediagnoser, traume- og dissosiative lidelser samt alvorlige personlighetsforstyrrelser. Aldersgruppen var fra 20 til 70 år og cirka 75 prosent av pasientene var kvinner. I tillegg ble skjemaene delt ut til alle faste ansatte, 15 stykker. Undersøkelsen ble gjennomført i løpet av to uker. Vi fikk inn skjema fra åtte pasienter i begge målingene, og henholdsvis ti og elleve fra personalet.

\section{Måleinstrumenter}

The Ward Atmosphere Scale (WAS)

WAS ble utarbeidet av Rudolf Moos sent på 60-tallet og er det mest brukte instrumentet for å måle forskjellige aspekter ved behandlingsmiljøet (16). Det er et selvutfyllingsskjema som måler hvordan både pasienter og personale opplever postmiljøet. I en studie (17) ved 54 avdelinger for psykotiske pasienter fant man at de variablene som har størst betydning for pasienttilfredsheten er et høyt nivå av engasjement, støtte, praktisk orientering og orden og organisasjon, og et lavt nivå av sinne og aggresjon og personalkontroll. Vi valgte derfor å fokusere på disse seks nøkkelvariablene. Hvert enkelt spørsmål skåres på en firetrinnsskala, mens variabelskårene kan variere fra 0 til 10 .

The Working Environment Scale - 10 (WES)

WES er et selvutfyllingsskjema hvor personalet svarer på spørsmål relatert til arbeidsmiljøet. Skjemaet måler fire dimensjoner ved arbeidsmiljøet: selvrealisering, arbeidsbyrde, konfliktnivå og angst, nervøsitet for å gå på jobb. I tillegg måles hvor tilfredse pasientene og personalet generelt er med posten.

\section{Intevensjonen}

I løpet av året fra den første WAS-målingen og til oppfølgingsmålingen ett år etter, ble det foretatt tre endringer i sengeposten på DPS'et. \ Det ble innført veiledning med fokus på rela- 


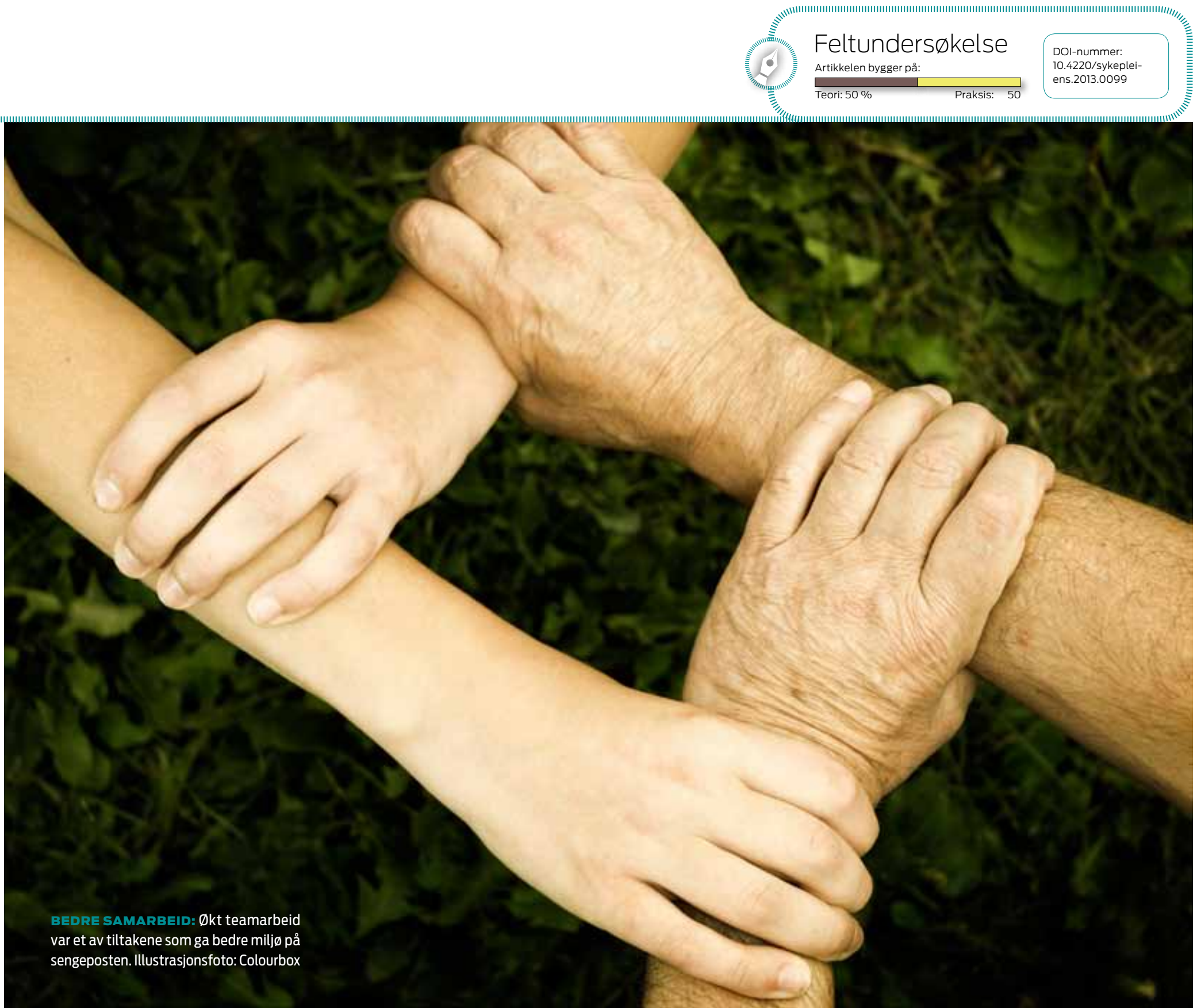

sjonen mellom pasientene og miljøpersonalet. I Det ble ansatt en psykologspesialist som hadde fokus på å veilede miljøpersonalet.

, Sengeposten gikk fra å arbeide med primærog sekundærkontaktsystem, til å arbeide i team.

\section{Veiledning}

Personalet fikk veiledning i 90 minutter en til to ganger i måneden i ni måneder i løpet av perioden fra den første WAS-målingen til oppfølgingsmålingen. Veiledningen vektla det relasjonelle aspektet i det miljøterapeutiske arbeidet. Verktøy som telefonstolpen (18) og mestringsskjemaet (19) bidro til en bedre oversikt over sammenhengen mellom sosiale data og sykdomshistorie og en bedre forståelse av pasientens utfordringer. Det ble brukt tid på å hjelpe miljøpersonalet til å erkjenne hvilke følelser pasienten vekket i dem, og å forstå egne motoverføringsreaksjoner bedre. Det gjorde det lettere å bruke motoverføringsreaksjonene i behandlingen og til å forebygge konflikter i behandlingsteamet (20-22).

Det ble lagt vekt på at de ansatte skulle gjenkjenne og anerkjenne pasientenes mestringsstrategier. Også symptomer ble sett på som mulige mestringsstrategier, som kunne være, eller ha vært hensiktsmessige, sett fra pasientens perspektiv. I neste omgang kunne de ansatte samarbeide med pasientene om utvikling av andre, mer hensiktsmessige mestringsstrategier.

En psykologspesialist ble ansatt i sengeposten noen måneder etter at den første WAS-målingen ble gjennomført. Hun fikk ansvar for å veilede, trygge og styrke miljøpersonalet slik at de kunne gi best mulig støtte til pasientene.

\section{Omorganisering}

Før omorganiseringen ble gjennomført jobbet man ut fra et primær- og sekundærkontaktsystem. Det innebar at to av miljøpersonalet hadde hovedansvaret for oppfølgingen av pasienten under innleggelsen og for behandlingsplaner.

\section{«De ansatte skulle aner- kjenne pasientenes mestringsstrategier.»}

Mange uttalte at de følte seg alene med ansvaret og at de gjerne skulle delt dette med flere. Ved å gå over til å arbeide i team gikk miljøpersonalet fra å være to som hadde ansvaret, til å bli et team på fem-seks personer rundt pasientene. Sengeposten prøvde å se på sammensetningen i teamene ut fra problematikken til den enkelte pasient, slik at personalet ville få mulighet til å fordype seg i områder de er interessert $i$.

\section{Resultater}

Tabell 1 viser gjennomsnittsskår og standardavvik for de seks nøkkelvariablene for pasienter og personale ved baseline og follow-up. For pasientene endret alle nøkkelvariablene seg i ønsket retning. Etter intervensjonen skåret 


\section{FAG}

\section{Psykiatrisk sykepleie}

Tabell 1: Gjennomsnitt og standardavvik for pasientene og personalet på de seks nøkkelvariablene i Ward Atmosphere Scale (WAS) ved baseline og follow - up.

\begin{tabular}{|c|c|c|c|c|}
\hline & \multicolumn{2}{|c|}{ Baseline } & \multicolumn{2}{|c|}{ Follow - up } \\
\hline & Gjennomsnitt & Standardavvik & Gjennomsnitt & Standardavvik \\
\hline WAS skåre, pasienter & \multicolumn{2}{|c|}{$N=8$} & \multicolumn{2}{|c|}{$N=8$} \\
\hline Engasjement & 4,57 & 2,23 & 5,38 & 1,34 \\
\hline Støtte & 5.00 & 1,74 & 6,81 & 1,39 \\
\hline Praktisk orientering & 5,28 & 3,18 & 6,31 & 1,85 \\
\hline Sinne & 3,04 & 1,52 & 2,08 & 1,14 \\
\hline Orden & 6,38 & 1,90 & 6,99 & 1,57 \\
\hline Personalkontroll & 4,53 & 1,58 & 4,17 & 1,32 \\
\hline WAS skåre, personalet & \multicolumn{2}{|c|}{$N=10$} & \multicolumn{2}{|c|}{$N=10$} \\
\hline Engasjement & 4,75 & 1,15 & 5,86 & 0,92 \\
\hline Støtte & 5,23 & 0,63 & 6,34 & 0,82 \\
\hline Praktisk orientering & 5,03 & 1,03 & 6,72 & 1,18 \\
\hline Sinne & 4,32 & 0,81 & 4,24 & 0,80 \\
\hline Orden & 5,70 & 1,02 & 7,11 & 1,13 \\
\hline Personalkontroll & 3,80 & 0,98 & 2,87 & 0,99 \\
\hline
\end{tabular}

pasientene høyere på variabler der man ønsker høye skårer: Engasjement, Støtte, Praktisk orientering og Orden og organisasjon. Pasienten skåert også lavere der det er mest ønskelig: Sinne og aggressiv atferd og Personalkontroll. Også personalskåringene endret seg $\mathrm{i} ø$ ønsket retning etter intervensjonen.

For å sammenlikne med andre norske psykia- triske poster valgte vi å lage en Z-skår ut fra et materiale bestående av 54 norske psykoseposter. Disse postene ble brukt som referanse, skårene ble omgjort til Z-skår og avviket fra gjennomsnittet på psykosepostene (0-linjen) ble angitt i antall standardavvik. Skårer som avvek ett standardavvik eller mer ble ansett som klart avvikende.

WAS-målingen ved baseline viste at posten

Figur 1: Endringer i WAS nøkkelvariabler sammenlignet med et norsk materiale bestående av 54 poster

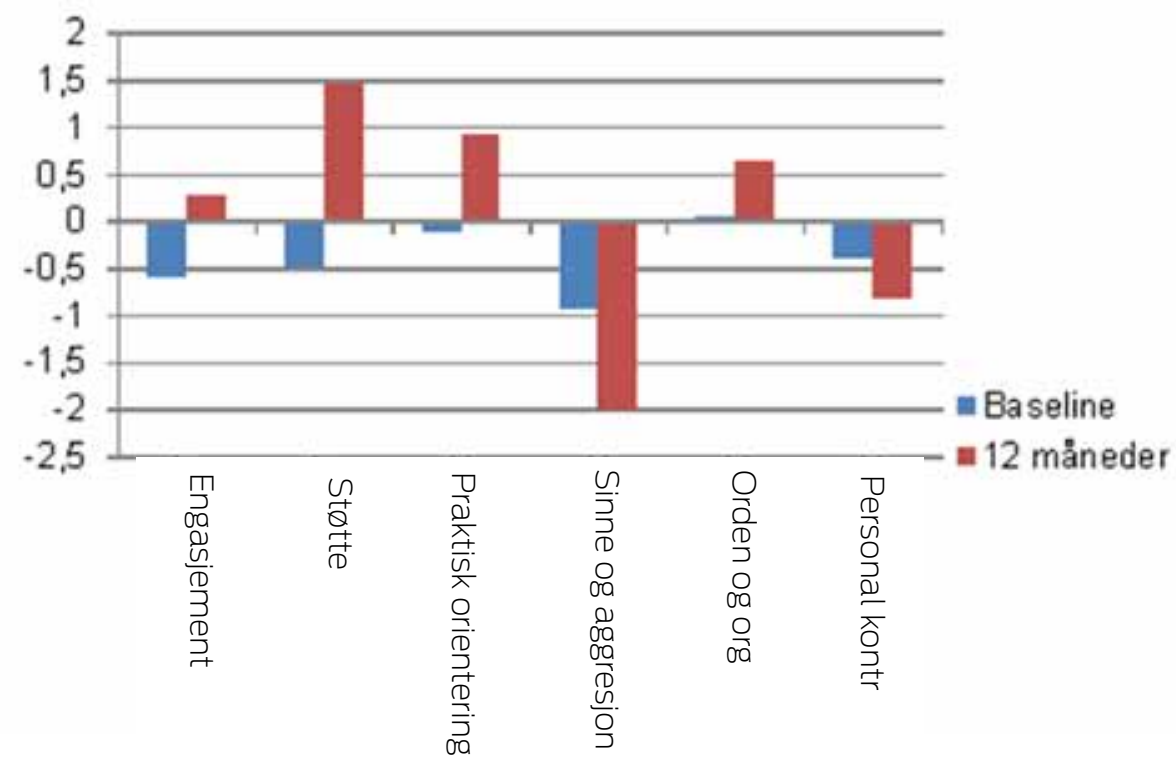

skåret lavt på alle WAS-variablene i forhold til en gjennomsnittspost (figur 1). Dette var bekymringsfullt for engasjement og støtte, som gikk i «uønsket» retning. For variablene sinne og aggressiv atferd og personalkontroll var den lave skåren gunstig. Ved oppfølgingsundersøkelsen har alle de seks nøkkelvariablene endret seg i ønsket retning. Det vil si at pasientene opplever et høyere nivå av engasjement, støtte, praktisk orientering og orden og organisasjon samt et lavere og mer ønskelig nivå av sinne og aggressiv atferd samt personalkontroll.

Ikke uventet gikk også tilfredshetskårene i $ø$ nsket retning. Tabell 2 viser at pasientene er mer generelt tilfreds med posten og at de er mer fornøyde med andre pasienter og personale. Den samme tendensen gjelder for personalet.

I denne undersøkelsen målte vi også personalets arbeidsmiljø. Litt uventet fant vi ikke de store endringene som ved de andre målene vi brukte. Ut fra tabell 3 ser vi at det bare er en liten endring fra den første WAS-målingen til oppøølgingsmålingen etter 12 måneder. Personalets mulighet til å realisere seg selv har økt noe, mens arbeidsbelastningen også har økt. Personalet angir at konfliktnivået og i hvilken grad de gruer og engster seg for å gå på jobb er likt ved begge målingene.

\section{Diskusjon}

Undersøkelsen viser at pasientenes og personalets oppfatning av postmiljøet er endret i positiv retning ett år etter at det er gjennomført konkrete endringer i sengeposten. Som antatt på forhånd viste resultatene en økning i tilfredsheten med postmiljøet både hos pasientene og personalet. Dette samsvarer med andre studier som har vist at det ofte ikke er nok med diskusjoner, men også behov for mer handlingsorientert tilnærming $(15,16)$. Et av målene med undersøkelsen var å finne ut om intervensjonen vi foretok ville bedre behandlingsmiljøet målt med WAS. Resultatene ved baseline viste et lavt nivå spesielt på miljøvariablene engasjement og støtte. Vi ønsket å få pasientene mer engasjert i behandlingen, og støtte dem i vanskelige situasjoner. For å få til det, satset vi på å styrke miljøpersonalet via veiledning. Oppfølgingsundersøkelsen viste at dette langt på vei hadde lyktes, ved at skårene på nøkkelvariablene i WAS endret seg i ønsket retning, samtidig som tilfredsheten blant pasientene og personalet økte.

Tuvesson og medarbeidere (23) fant i en studie at det er en sammenheng mellom postatmosfæren og miljøpersonalets oppfatning av det 
psykososiale arbeidsmiljøet. De konkluderer med at forbedring av postatmosfæren kan være en måte å forbedre arbeidsmiljøet på for miljøpersonalet. Vi fant at personalet opplevde større grad av selvrealisering, men også økt arbeidsbyrde.

Hensikten med å omorganisere til team var at personalet og pasientene skulle få færre per-

\section{«Vi ønsket å få pasi- entene mer engasjert i behandlingen.»}

soner å forholde seg til, og at personalet skulle få mulighet til å fordype seg i områder de var interessert i. De økte skårene på tilfredshet og selvrealisering tyder på at personalet får brukt seg selv og sine kunnskaper på en bedre måte. Opplevelsen av arbeidsbyrde har økt, men til tross for dette er altså både tilfredshet og opplevelse av selvrealisering bedre. Dette kan tyde på at opplevelse av arbeidsbyrde ikke har noen entydig sammenheng med tilfredshet og selvrealisering. Imidlertid har studier som har sett på sammenhengen mellom arbeidsmiljø og tilfredshet vist at det er en sammenheng mellom selvrealisering og generell tilfredshet med jobben (24). Dette samsvarer også med vår undersøkelse.

Denne undersøkelsen har flere begrensninger. Den inkluderte få pasienter og er foretatt ved kun én sengepost ved et DPS. Da det er foretatt flere endringer i sengeposten i året mellom målingene er det vanskelig å si hva som har størst betydning for de positive resultatene.

Tabell 2: Pasienter og personalets tilfredshet med postmiljøet, baseline og follow - up.

\begin{tabular}{|c|c|c|c|c|}
\hline & \multicolumn{2}{|c|}{ Baseline } & \multicolumn{2}{|c|}{ Follow - up } \\
\hline & Gjennomsnitt & Standardavvik & Gjennomsnitt & Standardavvik \\
\hline Tilfredshetsskåre, pasienter & \multicolumn{2}{|c|}{$\mathbf{N}=\mathbf{8}$} & \multicolumn{2}{|c|}{$\mathbf{N}=\mathbf{8}$} \\
\hline $\begin{array}{l}\text { Generell tilfredshet med } \\
\text { sengeposten }\end{array}$ & 3,57 & 1,40 & 4,13 & 0,84 \\
\hline Hvor godt de liker pasientene & 3,86 & 1,22 & 4,63 & 0,52 \\
\hline Hvor godt de liker personalet & 4,00 & 1,16 & 4,50 & 0,76 \\
\hline Tilfredshetsskåre, personalet & \multicolumn{2}{|c|}{$\mathbf{N}=11$} & \multicolumn{2}{|c|}{$\mathbf{N}=10$} \\
\hline $\begin{array}{l}\text { Generell tilfredshet med } \\
\text { sengeposten }\end{array}$ & 3,70 & 0,68 & 4,11 & 0,78 \\
\hline Hvor godt de liker pasientene & 4,10 & 0,32 & 4,33 & 0,50 \\
\hline Hvor godt de liker personalet & 4,20 & 0,42 & 4,66 & 0,50 \\
\hline
\end{tabular}

Tabell 3: Arbeidsmiljødimensjoner for personalet, baseline og follow - up

\begin{tabular}{|c|c|c|c|c|}
\hline & \multicolumn{2}{|c|}{ Baseline } & \multicolumn{2}{|c|}{ Follow - up } \\
\hline & Gjennomsnitt & Standardavvik & Gjennomsnitt & Standardavvik \\
\hline & \multicolumn{2}{|c|}{$N=11$} & \multicolumn{2}{|c|}{$N=10$} \\
\hline Selvrealisering & 3,28 & 0,58 & 3,61 & 0,79 \\
\hline Arbeidsbelastning & 3,13 & 0,63 & 3,66 & 0,61 \\
\hline Konfliktnivå & 2,63 & 0,53 & 2,61 & 0,69 \\
\hline $\begin{array}{l}\text { Angst/nervøsitet for } \\
\text { å gå på jobb }\end{array}$ & 2,00 & 0,77 & 2,05 & 0,91 \\
\hline
\end{tabular}

\section{Konklusjon}

Det er mulig å endre postatmosfæren i positiv retning ved å arbeide målrettet med relasjonen mellom pasienter og miljøpersonalet. Både postatmosfæren og pasient- og personaltilfredshet ble bedret. Når det gjelder personalets arbeidsmiljø, er resultatene mer usikre. Opplevelsen av selvrealisering er bedret til tross for $ø \mathrm{kt}$ arbeidsbyrde og et uendret, relativt høyt konfliktnivå. III

\section{REFERANSER}

Rittmannsberger H, Pachinger T, Keppelmuller P, Wancata J. Medication adherence among psychotic patients before admission to inpatient treatment. Psychiatric Services 2004: 55:174-9.

Friis S. Differensiering av terapeutiske miljøer. Nord. Psykiatr. Tidssk 1977:31:13-24.

3. Tveit Hanne, Haaland Thor, Knudsen Helge og Bøe Tor. Miljøterapeutiske prosesser i en psykiatrisk avdeling. Psykiatrisk Opplysningsfond 1997.

4. Langle G, Baum W, Wollinger A, Renner G, U'ren R, Schwarzler F, Eschweiler GW. Indicators of quality of inpatient psychiatric treatment: the patients' view. International Journal for Qality in Health Care 2003:15: 213-21.

. Johansson H, Eklund M. Patients' opinion on what constitutes good psychiatric care. Scand J Caring Sci 2003;7: 339-46.

6. Hansson L, Bjorkman T, Berglund I. What is important in psychiatric inpatien care? Qality of care from the patient's perspective. Qality Assurance in Health Care 1993;5: 41-7.

7. Melle I, Friis S, Hauff E, Island TK, Lorentzon S, Vaglum P: The importance of ward atmosphere in inpatients treatment of schizophrenia on short-term units. Psychiatric Serv 1996; 47:721-6.

8. Eklund M, Hansson L: Relationships between characteristics of the ward atmosphere and treatment outcome in a psychiatric day care unit based on occupational therapy. Acta Psychiatr Scand 1997; 95:329-35.
9. Timko C, Moos RH. Outcomes of the treatment climate in psychiatric and substance abuse programs. Journal of Clinical Psychology 1998a: 54:1137-50. . Timko C Moos RH. Determinants of the treatment climate in psychiatric and substance abuse programs: Implications for improving Patient outcomes. The Journal of Nervous and Mental Disease 1998b: 186: 96-103.

11. VaslumP. Friis S. KarterudS. Why are the results of milieu therapy forschi. Yale

12. Moos R. Evaluating treatment environments. The quality of psychiatric and substance abuse programs. Second Edition, Revised and Expanded (1997) Transaction Publishers, New Brunswick, New Jersey.

13. Smith J, Gross C, Roberts J. The evaluation of a therapeutic environment for patients with long-term mental illness as measured by the Ward Atmosphere Scale. J Ment Health 1996;5: 349-60.

14. Pierce WD, Trickett EJ, Moos RH. Changing ward atmosphere through staff discussion of the perceived ward environment. Arch Gen Psychiatry 1972;26: 35-41.

15. Friis S. From enthusiasme to resignation in a therapeutic community. A process evaluation of a mental hospital ward with the Ward Atmosphere Scale (WAS). J Oslo City Hosp 1981;31: 51-4.

16. James I, Milne DL, Firth H. A systematic comparison of feedback and staff discussion in changing the ward atmosphere. J Adv Nurs 1990:15: 329-36.
17. Røssberg Jl, Friis S. A suggested revision of the Ward Atmosphere Scale. Acta Psychiatrica Scandinavica 2003;108:374-80.

B. Thorgaard L. og Haga E. Gode relasjonsbehandlere og god miljøterapi. Hertervik forlag, 2006

19. Thorgaard L. Individuell mestring og mestring i relasjon. Hertervig forlag,

20. Røssberg Jl. Relasjoner mellom pasienter og stab. Hva fremmer et gunstig behandlingsresultat? I Oss imellom. Red. Bloch Thoresen, G.R. 2005:side $139-52$

21. Thorgaard L. Empatiens bevarelse i relasjonsbehandlingen i psykiatrien. Hertervik forlag, 2006

2. Belin S. Galskapens magt. Hans Reitzel 1999.

23. Tuvesson H, Wann-Hansson C, Eklund M. The Ward atmosphere important for the psychosocial work environment of nursing staff in psychiatric inpatient care. BMC Nursing 2011;10:12.

24. Røssberg Jl, Melle I, Opjordsmoen S, Friis S. Patient Satisfaction and Treatment Environment. A 20 year follow-up study from an acute psychiatric ward. Nord J of Psychiatry 2006;60:176-80.

Fagartikler kan sendes til torhild.apall@sykepleien.no 